\title{
Forced-air, vacuum, and hydro precooling of cauliflower (Brassica oleracea L. var. botrytis cv. Freemont): part I. Determination of precooling parameters
}

\author{
Ilknur ALIBAS ${ }^{1 *}$, Nezihe KOKSAL ${ }^{2}$
}

\begin{abstract}
The aim of the present study was to precool cauliflower using forced-air, vacuum and high and low flow hydro cooling methods. The weight of the precooled cauliflower heads $(5000 \pm 5 \mathrm{~g})$ was measured before they were placed in standard plastic crates. Cauliflower heads, whose initial temperature was $23.5 \pm 0.5^{\circ} \mathrm{C}$, were cooled until the temperature reached at $1{ }^{\circ} \mathrm{C}$. During the precooling process, time-dependent temperature and energy consumption were measured, and during vacuum precooling, the decreasing pressure values were recorded, and a curve of time-dependent pressure decrease (vacuum) was built. The most suitable cooling method to precool cauliflower in terms of cooling time and energy consumption was vacuum, followed by the high and low flow hydro and forced-air precooling methods, respectively. The highest weight loss was observed in the vacuum precooling method, followed by the forced-air method. However, there was an increase in the weight of the cauliflower heads in the high and low flow hydro precooling method. The best colour and hardness values were found in the vacuum precooling method. Among all methods tested, the most suitable method to precool cauliflower in terms of cooling and quality parameters was the vacuum precooling method.
\end{abstract}

Keywords: cauliflower; hydro cooling; forced-air cooling; vacuum cooling; energy consumption; weight loss.

\section{Introduction}

It is extremely important to maintain the quality and to delay deterioration of freshly harvested fruits and vegetables in order to prolong their consumption time. Factors including the continuation of respiration after harvest and enzyme degradation acceleration of the microorganisms' activities - which depends on the increase in temperature and on the presence of ethylene within the material - are considered as the main causes of biodegradation (Alibas \& Koksal, 2014; Sun \& Wang, 2004; Wang \& Sun, 2001). With the aim of minimizing the product loss and improving storage life and the quality of the products, various methods have already been developed. One of these methods is cooling. It is essential that products be cooled immediately after harvest to prevent deterioration, which normally takes place in fruits and vegetables during the postharvest period. In order to reduce water loss, yellowing, and wilting, the storage temperature of fresh produces is to be rapidly decreased immediately after harvest (Sankat \& Mujaffar, 1999).

Precooling is a way to remove the field heat of harvested produce. With the use of precooling methods, water loss is reduced and the storage life of perishable foodstuffs is extended (Brosnan \& Sun, 2003). Precooling usually involves the use of three different methods, forced-air, hydro, and vacuum precooling methods, depending on the characteristics of the products and the technology available.

The most common precooling method is forced-air precooling. With the effect of cold air, a product with high harvest temperature is cooled through convection, starting from the outer surface towards the inner surface. On the other hand, hydro precooling is a fast and efficient method of cooling, in which the water being cooled enters in contact with the produce providing cooling. However, some protection measures should be taken in order to prevent freezing of the product. Moreover, the products that are to be cooled by the hydro precooling method and the packing materials should be water-resistant. Another method used for the cooling of agricultural products is vacuum precooling. Vacuum precooling is based upon the principle that product temperature is decreased rapidly through evaporating the water existing in the product (Brosnan \& Sun, 2003). This method is defined as the removal of the latent heat of the water in the cooled product with rapid decrease in the water temperature as a consequence.

With the constant decrease in the pressure of the cooling system, the continuous evaporation of the product takes place. During vacuum cooling, free water evaporates at the temperature corresponding to the boiling (flash) point (Dostal \& Petera, 2004). When a product is subjected to vacuum, the flash point of the water decreases and some of the water boils until new equilibrium conditions occur (Wang \& Sun, 2004; Reno et al., 2011). When the vacuum precooling starts, with the effect of pressure, the water available in the interior of the product migrates to the surface of the product through boiling and evaporates. Therefore, cooling time becomes considerably shorter (Houska et al., 2003; McDonald \& Sun, 2000, 2001a, b; McDonald et al., 2000, 2001, 2002; Sun \& Wang, 2004; Wang \& Sun, 2001, 2002a, b, 2004; Rodrigues et al., 2012). 
The aims of the present study were: I) to treat cauliflower with forced air, hydro and vacuum precooling processes; II) to measure operating parameters such as temperature decrease, weight loss, energy consumption, and vacuum values during precooling; III) to model time-dependent temperature; IV) to determine the statistical differences between the values measured and the predicted values using the model; and V) to determine hardness and colour parameters after precooling.

\section{Materials and methods}

\subsection{Materials}

Cauliflowers (Brassica oleracea L. var. botrytis cv. Freemont) were grown in Gursu (Bursa, Turkey) by a professional cauliflower producer in October 2010. Plant materials were transported directly from the fields to the laboratory. All plants were of high quality and free from defects.

\subsection{Precooling systems}

Forced-air precooling system

The forced-air precooling system was composed of cooling cabinet, fan, controller and evaporator, condenser, compressor, and expansion valve.

The cooling cabinet $(850 \times 800 \times 1100 \mathrm{~mm}$ while the volume was $0.748 \mathrm{~m}^{3}$ ) was made of a $2 \mathrm{~mm}$ thick galvanized steel sheet. In order to create efficient insulation, the cooling cabinet was covered with a $12 \mathrm{~mm}$ thick fiberglass with heat transfer coefficient of $0.146538 \mathrm{~kJ} / \mathrm{m}^{2} \mathrm{~h}{ }^{\circ} \mathrm{C}$. Furthermore, the evaporator and the fan were located on the top in the back of the cooling cabinet. A digital temperature controller placed outside the cooling cabinet adjusted the temperature of the system, and an axial fan with five winglet tips with speed of $1400 \mathrm{~min}^{-1}$ and impeller diameter $160 \mathrm{~mm}$ were used in the system; the fan was operated by a $40 \mathrm{~W}$ electrical motor. Velocity of the air blown into the material by the fan was of $1 \mathrm{~m} \mathrm{~s}^{-1}$ (Wang \& Sun, 2002c, d). The evaporator consists of a copper pipe with diameter, length, and surface area of $13.5 \mathrm{~mm}, 8160 \mathrm{~mm}$, and $0.3459 \mathrm{~m}^{2}$, respectively. The condenser consists of a copper pipe with diameter, length, and surface area of $12 \mathrm{~mm}, 16400 \mathrm{~mm}$, and $0.6180 \mathrm{~m}^{2}$, respectively. Freon 12 (R12) was used as a refrigerant (Alibas \& Okursoy, 2012).

\section{Hydro precooling system}

The hydro precooling system was composed of: a cooling chamber, a storage tank, a circulating water pump, a showering unit, a pulverization unit, control panels, and an evaporator, a condenser, a compressor, and an expansion tank.

The cooling cabinet $(850 \times 800 \times 1100 \mathrm{~mm}$ while the volume was $0.748 \mathrm{~m}^{3}$ ) was made of a $2 \mathrm{~mm}$ thick galvanized steel sheet.

The water-spray unit with 3 nozzles was placed on the ceiling of the cooling chamber. The showering unit provided high flow hydro precooling, while the water-spray unit provided low flow hydro precooling in the form of fogging. On the one hand, the water flow of the water-spray unit was $2.5 \mathrm{~L} \mathrm{~min}^{-1}$; whereas the total water flow of both water-spray and showering unit was 7.5 $\mathrm{L} \mathrm{min}^{-1}$. Both units had two valves. The cooling system was activated by opening and closing valves. The cooling system was activated by opening and closing valves. The water tank was placed on the rear part of the main body of the system. It was made of stainless steel $(2 \mathrm{~mm}$ thickness, $980 \times 780 \times 700 \mathrm{~mm}$ size, and $0.5351 \mathrm{~m}^{3}$ volume). Two serpentine type evaporators were placed in the water tank to cool the water. The copper tube dimensions were: $17.5 \mathrm{~mm}$ diameter; $19.1 \mathrm{~m}$ length, and 1.05 $\mathrm{m}^{2}$ surface area. Water returning from the cooling cabinet to the system returned to the tank with a natural flow, and it was again forced to the system using a $55 \mathrm{~W}$ recirculating water pump. In order to create efficient insulation, the cooling cabinet was covered with a $12 \mathrm{~mm}$ thick fiberglass with heat transfer coefficient of $0.146538 \mathrm{~kJ} / \mathrm{m}^{2} \mathrm{~h}{ }^{\circ} \mathrm{C}$.

The condenser consists of copper pipe with diameter, length and surface area of $10 \mathrm{~mm}, 59.28 \mathrm{~m}$, and $1.8623 \mathrm{~m}^{2}$, respectively. An axial fan with five winglets was used to cool the condenser. The speed and dynamic impeller diameter of the axial fan were $1750 \mathrm{~min}^{-1}$ and $400 \mathrm{~mm}$, respectively. The fan was operated by $60 \mathrm{~W}$ mono-phase electrical motor (Alibas \& Okursoy, 2009, 2012).

\section{Vacuum precooling system}

The vacuum precooling system consisted of: a vacuum tank, a vacuum pump, an evaporator, a condenser, a compressor, and an expansion valve.

The cylindrical vacuum tank was made of a $6 \mathrm{~mm}$ thick sheet steel ( $0.6 \mathrm{~m}$ diameter and $1 \mathrm{~m}$ length). In order to create efficient insulation, the cooling cabinet was covered with a $12 \mathrm{~mm}$ thick fiberglass with heat transfer coefficient of $0.146538 \mathrm{~kJ} / \mathrm{m}^{2} \mathrm{~h}{ }^{\circ} \mathrm{C}$.

The evaporator consists of a copper pipe with diameter, length, and surface area were $13.5 \mathrm{~mm}, 7.35 \mathrm{~m}$, and $0.3116 \mathrm{~m}^{2}$, respectively.

An evaporator was used so that water, which was removed from the product in the form of wet steam, could be used again by turning into fluid. The use of an evaporator in the vacuum tank increases the efficiency of the vacuum pump (Alibas \& Okursoy, 2009, 2012). The condenser consists of a copper pipe with diameter, length, and surface area of $11.8 \mathrm{~mm}, 7.33 \mathrm{~m}$, and $0.2716 \mathrm{~m}^{2}$, respectively. An axial fan with five winglets was used to cool the condenser. The speed and dynamic impeller diameter of the axial fan were $1400 \mathrm{~min}^{-1}$ and $260 \mathrm{~mm}$, respectively. The fan was operated by $40 \mathrm{~W}$ mono-phase electrical motor

A laboratory type greasy vacuum pump (Carpanelli MMDE80B4, Italy), with operating conditions of 220/240V , $50 / 60 \mathrm{~Hz}$, and $5.1 / 4.8 \mathrm{~A}$, was used to reduce the pressure of the system.

\subsection{Precooling methods}

In the present study, four different precooling methods: forced-air (AC), vacuum (VC), high flow (Lf-HC) hydro, and low flow hydro (Hf-HC) were tested.

The products to be cooled, cauliflower heads, were placed in the cooling cabinets and weighed after precooling using a $1 \mathrm{~g}$ 
accuracy balance (Baster-plus, LCB-2, Turkey); they weighed $5000 \pm 5 \mathrm{~g}$ before they were placed in plastic crates.

During cooling in the precooling systems, a data-logger (Datalogger-10, Turkey) capable of measuring temperature from 10 channels was used in order to measure the timedependent temperature decrease. A total of ten temperature probes were placed in the pre-coolers to determine the decrease in temperature of the material. Two of these temperature probes were placed at the centre of the crate containing the products. Four of them were placed in the right, left, front and rear of the crate. Two of them were at the bottom and top of the crate, while the other two were placed in the tank to measure the ambient temperature. Therefore, time-dependent decrease in temperature was recorded using a data logger set at a $1 \mathrm{~s}$ interval.

Five analog thermometers were used to measure the temperature outside the cooling, at the temperature range of $0.1{ }^{\circ} \mathrm{C}$.

In order to measure energy consumption, a mono-phase electric meter (Kaan, 001, Turkey) was used in the forced-air and vacuum precooling systems, while a tri-phase electric meter (Kaan, 002, Turkey) was used in the hydro precooling system. The precooling systems were connected to the energy meter to determine the energy consumption during the process of precooling.

All precooling process continued until both probes placed at the center of the plastic boxes reached $1{ }^{\circ} \mathrm{C}$ (Zhang \& Sun, $2006 a, b)$. Air velocity in the forced-air precooling system was $1 \mathrm{~m} \mathrm{~s}^{-1}$. The hydro precooling method was applied in two ways: with high flow using the showering technique and with low flow using the pulverization technique. The flow rates of the showering and pulverization units were $7.5 \mathrm{~L} \mathrm{~min}^{-1}$ and $2.5 \mathrm{~L} \mathrm{~min}^{-1}$, respectively.

Vacuum, in the vacuum precooling system, was measured using a data logger (Datalogger-10, Turkey), and an analogue vacuum meter (Viot 69044, US) and a mercury-manometer were also used to obtain pressure value. When the pressure in the system reached $2.9 \mathrm{kPa}$, which is equal to the flash point with maximum evaporation, the cooling system was activated in order to prevent intense evaporation. The cooling system was used for the condensation of water vapour and not for cooling; therefore, the system was operated at the lowest level.

\subsection{Colour parameters and hardness}

The quality parameters, hardness, colour, and weight, of the cauliflower heads were measured after precooling. A total of ten cauliflowers (representing the total average) were used for colour determination. After calibrating the colorimeter (CR 400, Konica- Minolta, Osaka, Japan) using a standard white tile, the colour parameters were determined. Accordingly, $L$ corresponds to whiteness-blackness or brightness and ranges between 0 (black) and 100 (white); a corresponds to greenness-redness transition and ranges between -50 (green) and +50 (red); $b$ corresponds to blueness-yellowness transition and ranges from -50 (blue) to +50 (yellow). The chroma of the colour $(C)$ and the angle of the colour $(\alpha)$ were automatically determined using a colorimeter (Alibas, 2014; Alibas \& Koksal, 2014).

The hardness of fresh products and of those exposed to precooling was measured using a penetrometer (FT 327, Italy), which was placed on a table (Bosch BS 45, Germany).

\subsection{Statistical methods}

The experiments were performed in three replications. The mean of the data obtained and variance analysis were analyzed using a SPSS 17.0. Non-linear regression analysis was performed using the NLREG (NLREG version 6.3) to estimate the cooling rate parameter $(C R)$ of the common cooling equation (Eq. (1)).

Thus, with the values measured, the predicted values of the statistical program related to the temperature were determined. The standard error of the estimate (SEE) and coefficients of determination $\left(R^{2}\right)$ were determined by nonlinear regression analysis (Alibas \& Okursoy, 2009, 2012):

$T=T_{i}+\left[T_{m} \cdot \exp (C R . t)\right]$

Where: $T$, temperature measured based on the data collection device $\left({ }^{\circ} \mathrm{C}\right)$; $T_{i}$, the desired temperature value of the product after the precooling process $\left({ }^{\circ} \mathrm{C}\right) ; T_{m}$, the temperature of the material before the precooling process $\left({ }^{\circ} \mathrm{C}\right) ; C R$, cooling coefficient, and $t$, time.

\section{Results and discussion}

The curve of the precooling of cauliflower using the forcedair, vacuum, and high and low flow hydro cooling processes as a function of the time-dependent temperature decrease is shown in Figure 1. The initial temperature values of the cauliflower heads which were to be cooled with forced-air, vacuum, and high and low flow hydro cooling processes were $23^{\circ} \mathrm{C}, 24^{\circ} \mathrm{C}$, $24^{\circ} \mathrm{C}$, and $23.5^{\circ} \mathrm{C}$, respectively; the cauliflower heads were cooled until $1{ }^{\circ} \mathrm{C}$.

It was found that 36 minutes of vacuum precooling was the shortest method used, whereas forced-air precooling was the longest, 184 minutes. Similar findings were found by several authors (Desmond et al., 2002; Jackman et al., 2007; Cheng, 2006; Zhang \& Sun, 2006a, b). Accordingly, vacuum precooling was 5.11 times faster than forced-air precooling. The high and low flow hydro precooling lasted 64 and 84 minutes, respectively. A 1.31-fold decrease in cooling time was obtained with the increase of water flow from $2.5 \mathrm{~L} \mathrm{~min}^{-1}$ to $7.5 \mathrm{~L} \mathrm{~min}^{-1}$. It was concluded that the cooling times in the hydro precooling with high and low flow was, respectively, 1.78 and 2.33 times higher than those of the vacuum precooling method. Yet, there was a decrease of 2.88 and 2.19 times in comparison to the cooling time of forced-air precooling method. Similar findings were found by several authors (McDonald et al., 2000, 2001; Sun \& Wang, 2000).

The statistical data obtained during the precooling of cauliflower with forced-air, vacuum, and high and low flow hydro cooling methods are shown in Table 1 . The highest regression coefficient $\left(R^{2}\right), 0.9989$, was found in the forced-air 


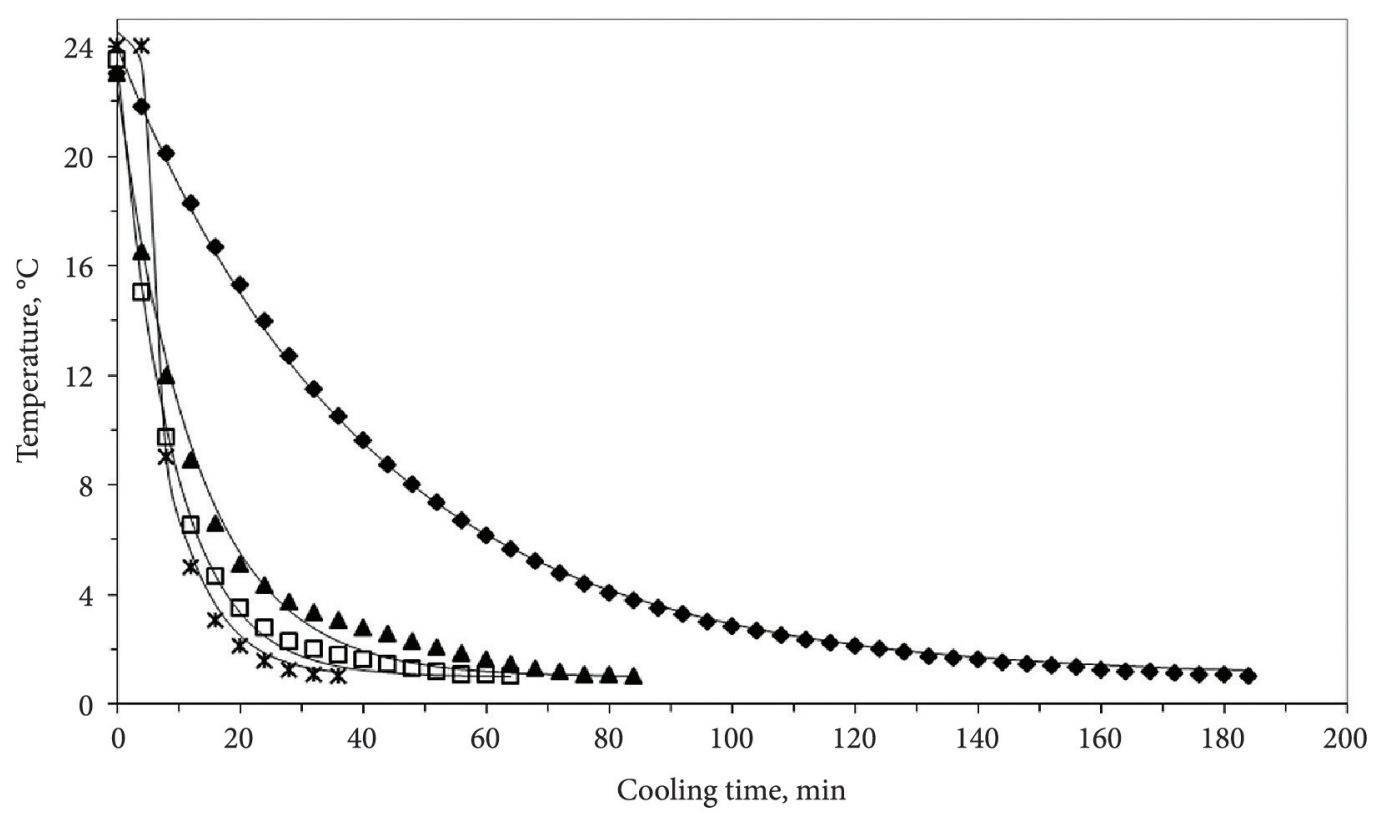

Figure 1. Time-dependent temperature decrease during the precooling of cauliflower using forced-air, vacuum, hydro with low flow and hydro cooling processes; ${ }^{\star}, \mathrm{VC} ; \square, \mathrm{Hf}-\mathrm{HC} ; \boldsymbol{\Delta}, \mathrm{Lf}-\mathrm{HC} ; \star$ AC.

Table 1. Statistical data obtained during the cooling of cauliflower using different precooling methods.

\begin{tabular}{cccc}
\hline Precooling Methods & Standard Error of Estimate (SEE) ${ }^{* *}$ & $\mathrm{R}^{2 * *}$ & ${\text { Cooling Rate }(\mathrm{CR})^{* *}}^{* *}$ \\
\hline AC & 0.206335 & 99.89 & 0.024763 \\
VC & 0.568599 & 99.52 & 0.137713 \\
Lf-HC & 0.520294 & 99.19 & 0.077962 \\
Hf-HC & 0.263663 & 99.83 & 0.112966 \\
\hline
\end{tabular}

${ }^{\star *} \mathrm{P}<0.01$. Column mean values with different superscripts are significantly different.

cooling system while the lowest " $R^{2 \text { ", }} 0.9919$, was observed in the low flow hydro precooling system. The regression coefficient of high flow hydro precooling system and vacuum precooling system were 0.9983 and 0.9952 , respectively. The standard error of estimate (SEE) and cooling rate $(C R)$ were also given in Table 1. Accordingly, it was found that the cooling coefficients of forced-air, low and high flow hydro, and vacuum precooling systems were $0.025,0.078,0.113$, and 0.138 , respectively.

Pressure and time during the vacuum precooling of the cauliflower heads are shown in Figure 2. Vacuum precooling lasted 36 minutes, and it reached $3.01 \mathrm{kPa}$. The flash point of $0.66 \mathrm{kPa}$ was reached in $4^{\text {th }}$ minutes, which was the minimum pressure value in 10 minutes. The system pressure remained at $0.66 \mathrm{kPa}$ until the end of the vacuum cooling process. Alibas \& Okursoy (2009) cooled spinach with vacuum and found similar vacuum values.

Energy consumption values of the cauliflower heads during all precooling process are given in Table 2. According to Table 2, the highest energy consumption during the precooling process of cauliflower heads was measured using the forcedair precooling method with $1.13 \mathrm{kWh}$. The results of the low and high flow hydro and vacuum precooling methods were $0.78 \mathrm{kWh}, 0.67 \mathrm{kWh}$, and $0.51 \mathrm{kWh}$, respectively. Similar results were found by Alibas \& Okursoy (2009). Forced-air precooling, which was the most expensive method, showed 2.22 times more energy consumption than that of the vacuum precooling system, which was the least expensive method. The energy consumption of the low flow hydro precooling method was 1.16 times higher than that of the high flow hydro precooling method. In the present study, the high flow hydro precooling method was way less expensive than the hydro low flow precooling method, in terms of energy consumption. Alibas \& Okursoy (2009) precooled the spinach using vacuum, forcedair and high and low flow hydro cooling methods to determine the energy consumption of these cooling processes. The authors found that the vacuum precooling method was the least energy consumption method, followed by the high and low flow hydro and forced-air precooling methods, respectively. Alibas \& Okursoy (2012) precooled fava beans using the vacuum, forcedair, and hydro precooling methods and determined the energy consumptions of these systems. They found that the least energy consumption method was vacuum, followed by the hydro and forced-air precooling methods, respectively.

Power values required during the precooling of cauliflower with forced-air, vacuum, high flow and low flow hydro precooling methods are given in Table 2. Accordingly, among the precooling methods tested, vacuum required the highest power, $0.8516 \mathrm{~kW}$, followed by high flow hydro, $0.6268 \mathrm{~kW}$, low 

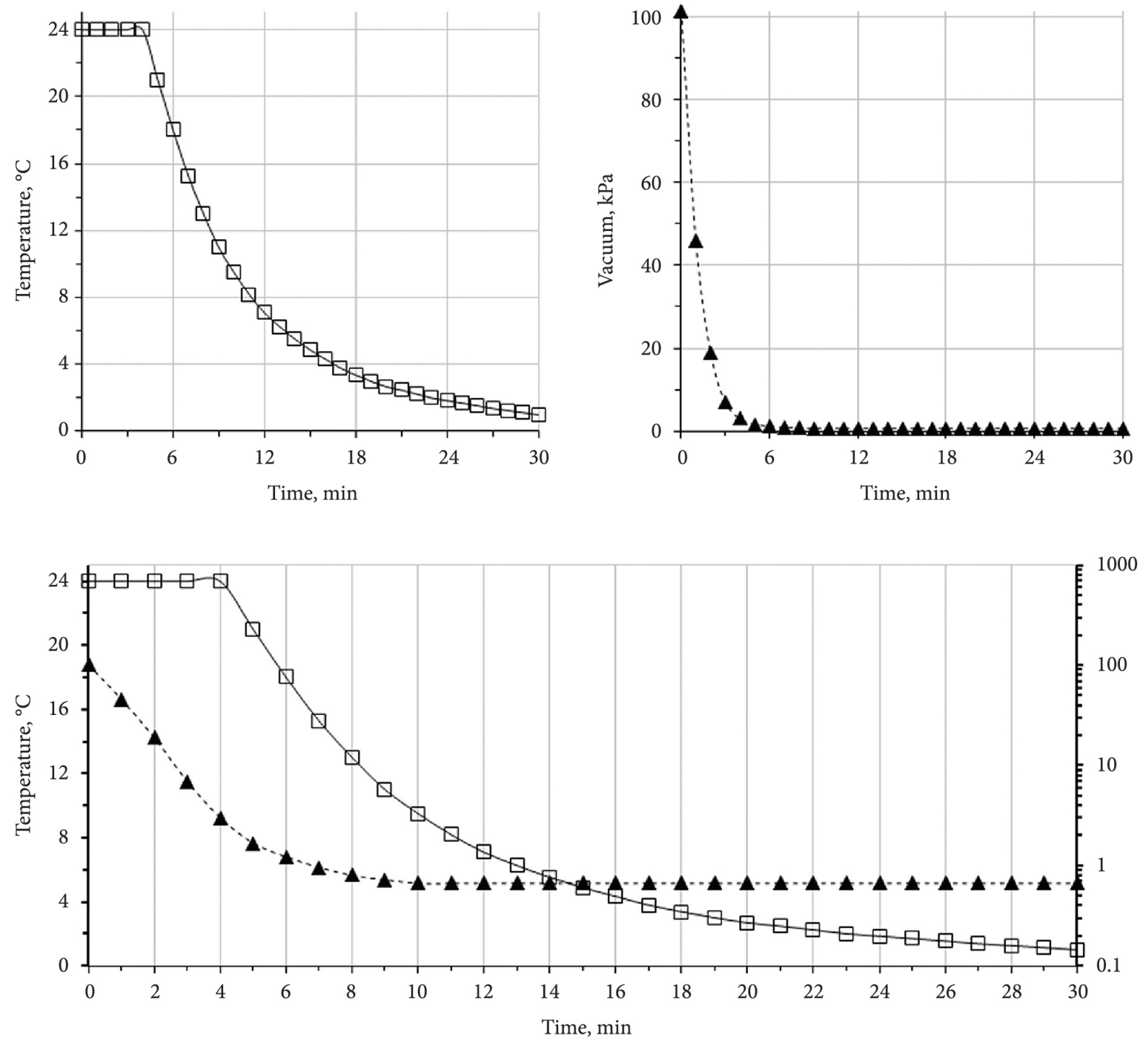

Figure 2. Relationship between measured values of temperature, pressure, and time during vacuum precooling of cauliflower.

Table 2. Precooling parameters of cauliflower heads.

\begin{tabular}{|c|c|c|c|c|}
\hline Precooling Methods & Precooling Time $(\min )^{* *}$ & Energy Consumption $(\mathrm{kWh})^{* *}$ & Power $(\mathrm{kW})^{* *}$ & Weight Difference $(\%)^{* *}$ \\
\hline $\mathrm{AC}$ & $184 \pm(3.06)^{\mathrm{d}}$ & $1.13 \pm(0.0289)^{\mathrm{d}}$ & $0.3684 \pm(0.00419)^{\mathrm{a}}$ & $-2.89 \pm(0.1610)^{c}$ \\
\hline $\mathrm{VC}$ & $36 \pm(2.08)^{\mathrm{a}}$ & $0.51 \pm(0.0208)^{\mathrm{a}}$ & $0.8516 \pm(0.01410)^{\mathrm{d}}$ & $-4.55 \pm(0.0436)^{\mathrm{d}}$ \\
\hline Lf-HC & $84 \pm(4.62)^{c}$ & $0.78 \pm(0.0436)^{\mathrm{b}}$ & $0.5571 \pm(0.00357)^{\mathrm{b}}$ & $2.81 \pm(0.0436)^{\mathrm{b}}$ \\
\hline Hf-HC & $64 \pm(2.52)^{\mathrm{b}}$ & $0.67 \pm(0.0451)^{\mathrm{b}}$ & $0.6268 \pm(0.01700)^{c}$ & $3.65 \pm(0.0666)^{\mathrm{a}}$ \\
\hline
\end{tabular}

** $\mathrm{P}<0.01$. Column mean values with different superscripts are significantly different.

flow hydro, $0.5571 \mathrm{~kW}$, and forced-air,0.3684 kW, precooling methods, respectively. The power required by the vacuum precooling method was 2.31 times higher than that of forced-air precooling method. Furthermore, the power required of the high flow hydro method was 1.13 times higher than that of the low flow hydro precooling method. These results contradict those found by Alibas \& Okursoy (2012).

The differences in weight values after applying the precooling methods are given Table 2. It can be seen that the cauliflower heads precooled with the high and low flow hydro method had $3.65 \%$ and $2.81 \%$ of weight gain, respectively, whereas in those precooled with forced-air and vacuum, the weight loss increased by $2.89 \%$ and $4.55 \%$, respectively. Similar results were found by several authors (McDonald et al., 2000, 2002; Sun \& Wang, 2000; Desmond et al., 2002; Zhang \& Sun, 2006a, b; Jackman et al., 2007).

The values of hardness of the cauliflower heads obtained during all precooling process are given in Figure 3a. According to Figure 3a, the hardness of fresh cauliflower heads was $5.75 \mathrm{~kg}$ after all precooling processes. The highest hardness value, $5.6 \mathrm{~kg}$, 
(a)

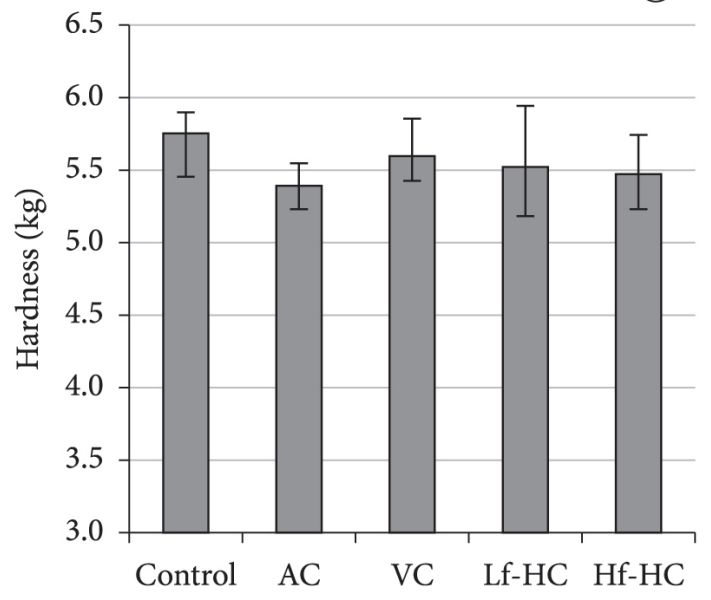

Precooling methods

(c)

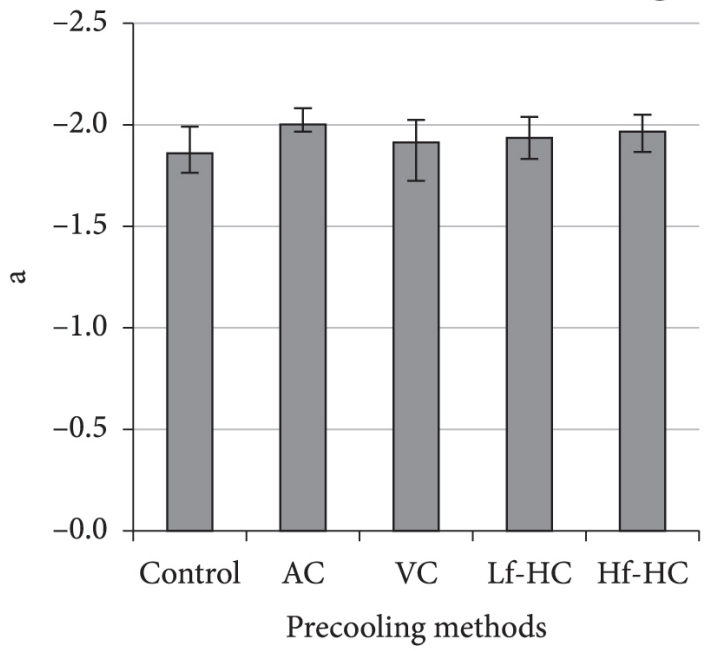

(e)

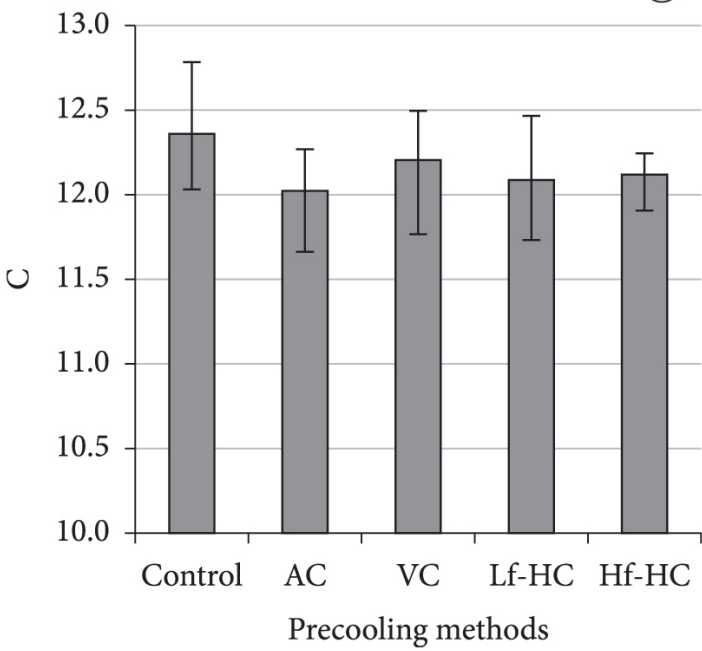

(b)

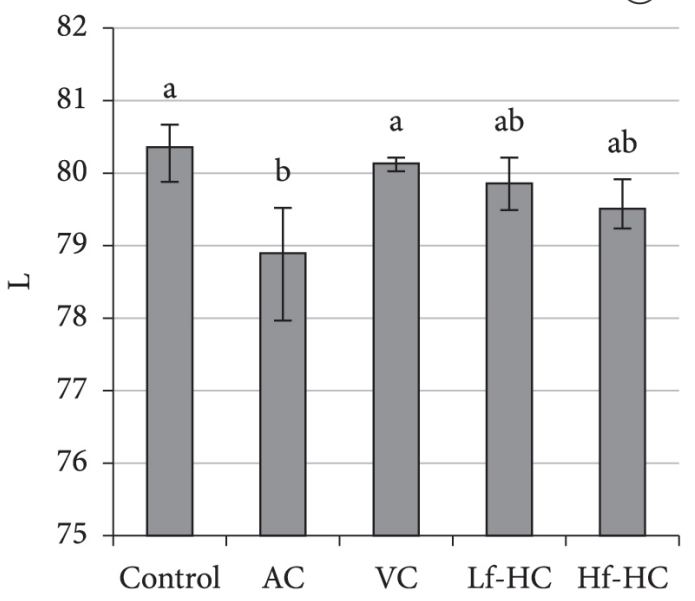

Precooling methods $(p<0.01)$

(d)

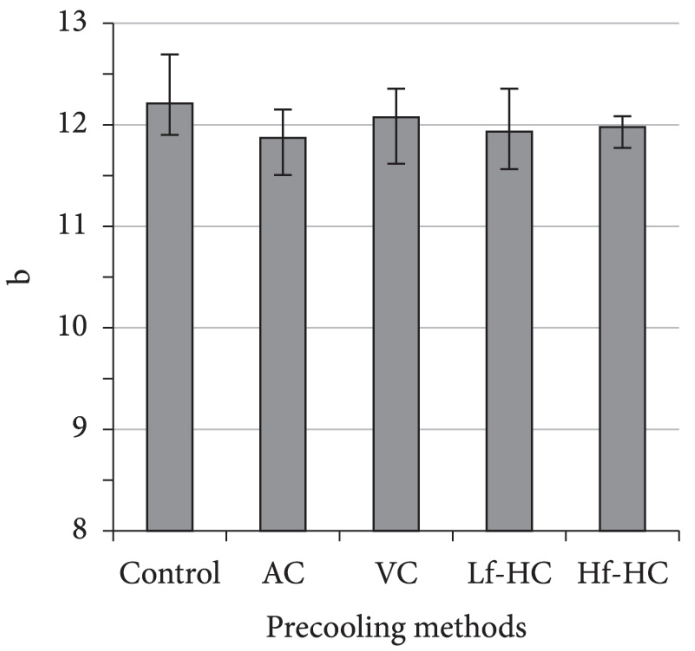

(f)

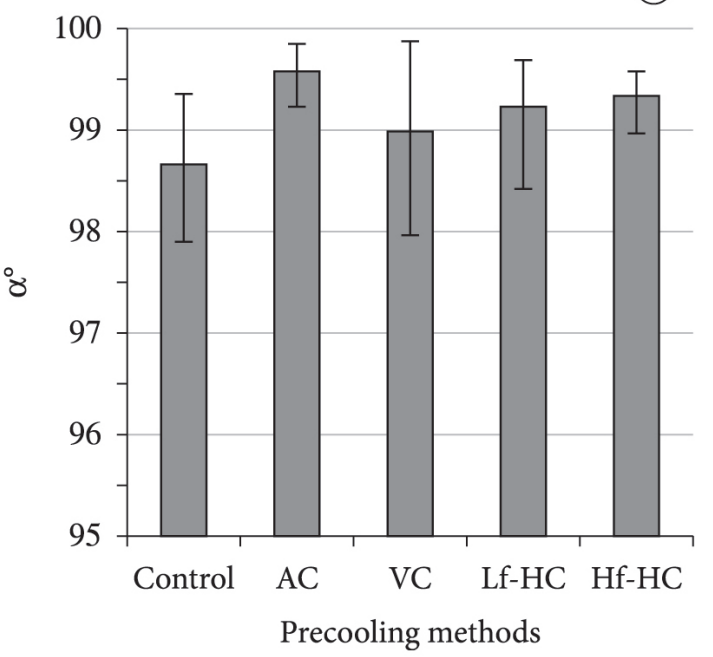

Figure 3. Hardness and color changes $(L, a, b, C$ and $\alpha$ ) of the control and precooled cauliflower heads using vacuum (VC), forced-air (AC), high flow hydro (Hf-HC) and low flow hydro precooling methods (Lf-HC). 
was found in the vacuum precooling method, whereas the lowest value, $5.4 \mathrm{~kg}$, was obtained in the forced-air precooling method. The hardness values of the vacuum, low and high flow hydro, and forced-air precooling methods decreased at the rate of $0.026 \%$, $0.039 \%, 0.049 \%$, and $0.065 \%$, respectively.

The colour parameters, $L, a, b, C$ and $\alpha$, obtained for all precooling process are given in Figure 3. According to Figure 3, Brightness, redness, yellowness, and chroma parameters of control samples were $80.34,-1.85,12.19$, and 12.33 , respectively. The best colour parameters of cauliflower heads were found using the vacuum precooling method. Brightness, redness, yellowness, and chroma parameters of vacuum precooled materials were $80.15,-1.90,12.04$ and 12.19 , respectively. The worse colour parameters of cooled cauliflower heads were obtained in the forced-air precooling method, with $\mathrm{L}, \mathrm{a}, \mathrm{b}$ and $\mathrm{C}$ values of $78.90,-1.99,11.83$, and 12.00 , respectively. Brightness $(\mathrm{L})$ is the most important colour parameter when determining the parameters of a white. Accordingly, the best brightness colour value, 80.15 , was obtained in the vacuum precooling process.

\section{Conclusion}

In the present study, cauliflower heads were cooled using the forced-air, vacuum, high and low flow hydro precooling methods. Vacuum precooling had the lowest cooling time and the lowest energy consumption, followed by high and low flow hydro and forced air precooling methods. During the precooling process, weight gain was observed in the cauliflower heads precooled with the low and high flow hydro method, while those precooled with forced-air and vacuum methods exhibited weight loss. The cooling methods used were compared in terms of power requirement; the vacuum precooling method had the maximum power requirement, followed by the low and high flow hydro and forced-air precooling methods, respectively. Regression coefficients $\left(R^{2}\right)$ were between $99.89 \%$ and $99.19 \%$. In terms of brightness $(L)$, the value indicating the brightness and white colour (colour value closest to the fresh product) was found in the cauliflower heads precooled with the vacuum method. Among all of the precooling methods used, vacuum is the most suitable method in terms of energy consumption, cooling time, colour, and hardness.

\section{References}

Alibas, I. (2014). Microwave, air and combined microwave-air drying of grape leaves (Vitis vinifera L.) and the determination of some quality parameters. International Journal of Food Engineering, 10(1), 69-88. http://dx.doi.org/10.1515/ijfe-2012-0037.

Alibas, I., \& Koksal, N. (2014). Convective, vacuum and microwave drying kinetics of mallow leaves and comparison of color and ascorbic acid values of three drying methods. Food Science and Technology, 34(2), 358-364.

Alibas, I., \& Okursoy, R. (2009). Determination of operating and quality parameters during air blast, vacuum and hydro pre-cooling of spinach. Journal of Agricultural Machinery Science, 5(2), 149-160. [in Turkish]

Alibas, İ., \& Okursoy, R. (2012). A comparison study of some operating parameters during vacuum, air and hydo pre-cooling of faba beans, and determination of the quality parameters during storage period. Journal of Agricultural Machinery Science, 8(2), 185-197. [in Turkish]

Brosnan, T., \& Sun, D. W. (2003). Influence of modulated vacuum cooling on the cooling rate, mass loss and vase life of cut lily flowers. Biosystems Engineering, 86(1), 45-49. http://dx.doi.org/10.1016/ S1537-5110(03)00101-6.

Cheng, H.-P. (2006). Vacuum cooling combined with hydrocooling and vacuum drying on bamboo shoots. Applied Thermal Engineering, 26(17-18), 2168-2175. http://dx.doi.org/10.1016/j. applthermaleng.2006.04.004.

Desmond, E. M., Kenny, T. A., \& Ward, P. (2002). The effect of injection level and cooling method on the quality of cooked ham joints. Meat Science, 60(3), 271-277. http://dx.doi.org/10.1016/S03091740(01)00133-4. PMid:22063398

Dostal, M., \& Petera, K. (2004). Vacuum cooling of liquids: mathematical model. Journal of Food Engineering, 61(4), 533-539. http://dx.doi.org/10.1016/S0260-8774(03)00223-1.

Houska, M., Sun, D. W., Landfeld, A., \& Zhihang, Z. (2003). Experimental study of vacuum cooling of cooked beef in soup. Journal of Food Engineering, 59(2-3), 105-110. http://dx.doi. org/10.1016/S0260-8774(02)00435-1.

Jackman, P., Sun, D. W., \& Zheng, L. (2007). Effect of combined vacuum cooling and air blast cooling on processing time and cooling loss of large cooked beef joints. Journal of Food Engineering, 81(1), 266-271. http://dx.doi.org/10.1016/j.jfoodeng.2006.10.026.

McDonald, K., \& Sun, D. W. (2000). Vacuum cooling technology for the food processing industry: a review. Journal of Food Engineering, 45(2), 55-65. http://dx.doi.org/10.1016/S0260-8774(00)00041-8.

McDonald, K., Sun, D. W., \& Kenny, T. (2000). Comparison of the quality of cooked beef products cooled by vacuum cooling and by conventional cooling. Lebensmittel-Wissenschaft und-Technologie, 33(1), 21-29. http://dx.doi.org/10.1006/fstl.1999.0603.

McDonald, K., \& Sun, D. W. (2001a). The formation of pores and their effects in a cooked beef product on the efficiency of vacuum cooling. Journal of Food Engineering, 47(3), 175-183. http://dx.doi. org/10.1016/S0260-8774(00)00111-4.

McDonald, K., \& Sun, D. W. (2001b). Effect of evacuation rate on the vacuum cooling process of a cooked beef product. Journal of Food Engineering, 48(3), 195-202. http://dx.doi.org/10.1016/S02608774(00)00158-8.

McDonald, K., Sun, D. W., \& Kenny, T. (2001). The effect of injection level on the quality of a rapid vacuum cooled cooked beef product. Journal of Food Engineering, 47(2), 139-147. http://dx.doi. org/10.1016/S0260-8774(00)00110-2.

McDonald, K., Sun, D. W., \& Lyng, J. G. (2002). Effect of vacuum cooling on the thermophysical properties of a cooked beef product. Journal of Food Engineering, 52(2), 167-176. http://dx.doi. org/10.1016/S0260-8774(01)00100-5.

Reno, M. J., Prado, M. E. T., \& Resende, J. V. (2011). Microstructural changes of frozen strawberries submitted to pre-treatments with additives and vacuum impregnation. Ciência e Tecnologia de Alimentos, 31(1), 247-256. http://dx.doi.org/10.1590/S010120612011000100038.

Rodrigues, L. G. G., Cavalheiro, D., Schmidt, F. C., \& Laurindo, J. B. (2012). Integration of cooking and vacuum cooling of carrots in a same vessel. Ciência e Tecnologia de Alimentos, 32(1), 187-195.

Sankat, C. K., \& Mujaffar, S. (1999). Water balance in cut Anthurium flowers in storage and its effects on quality. Acta Horticulturae, $368,723-732$. 
Sun, D. W., \& Wang, L. (2000). Heat transfer characteristics of cooked meats using different cooling methods. International Journal of Refrigeration, 23(7), 508-516. http://dx.doi.org/10.1016/S01407007(99)00079-1.

Sun, D. W., \& Wang, L. (2004). Experimental investigation of performance of vacuum cooling for commercial large cooked meat joints. Journal of Food Engineering, 61(4), 527-532. http://dx.doi. org/10.1016/S0260-8774(03)00220-6.

Wang, L., \& Sun, D. W. (2001). Rapid cooling of porous and moisture foods by using vacuum cooling technology. Trends in Food Science \& Technology, 12(5-6), 174-184. http://dx.doi.org/10.1016/S09242244(01)00077-2.

Wang, L., \& Sun, D. W. (2002a). Modelling vacuum cooling process of cooked meat - Part 1: analysis of vacuum cooling system. International Journal of Refrigeration, 25(7), 854-861. http://dx.doi. org/10.1016/S0140-7007(01)00094-9.

Wang, L., \& Sun, D. W. (2002b). Modelling vacuum cooling process of cooked meat - Part 2: mass and heat transfer of cooked meat under vacuum pressure. International Journal of Refrigeration, 25(7), 862871. http://dx.doi.org/10.1016/S0140-7007(01)00095-0.
Wang, L., \& Sun, D. W. (2002c). Evaluation of performance of slow air, air blast and water immersion cooling methods in the cooked meat industry by the finite element method. Journal of Food Engineering, 51(4), 329-340. http://dx.doi.org/10.1016/S0260-8774(01)00075-9.

Wang, L., \& Sun, D. W. (2002d). Modelling three-dimensional transient heat transfer of roasted meat during air blast cooling by the finite element method. Journal of Food Engineering, 51(4), 319-328. http:// dx.doi.org/10.1016/S0260-8774(01)00074-7.

Wang, L., \& Sun, D. W. (2004). Effect of operating conditions of a vacuum cooler on cooling performance for large cooked meat joints. Journal of Food Engineering, 61(2), 231-240. http://dx.doi. org/10.1016/S0260-8774(03)00095-5.

Zhang, Z., \& Sun, D. W. (2006a). Effects of cooling methods on the cooling efficiency and quality of cooked rice. Journal of Food Engineering, 77(2), 269-274. http://dx.doi.org/10.1016/j. jfoodeng.2005.06.029.

Zhang, Z., \& Sun, D. W. (2006b). Effects of cooling methods on the cooling efficiency and qualities of cooked broccoli and carrot slices. Journal of Food Engineering, 77(2), 320-326. http://dx.doi. org/10.1016/j.jfoodeng.2005.06.038. 